\title{
Influence of Bearing Defects on Dynamical Behavior of An Elastic Shaft
}

\author{
OLIVIER BONNEAU and JEAN FRENNE \\ Laboratoire de Mécanique des Solides SP2MI-Bd 3, Téléport 2-BP 179-86960 FUTUROSCOPE Cedex FRANCE
}

\begin{abstract}
A study of an elastic rotor supported by two defect bearings is presented. The bearing behavior must be considered non-linear because of the defect effects. The rotor is modelled by typical beam finite element including effects such as gyroscopic effect. The dynamic behavior is analysed using an unsteady time integration procedure. A modal technique is used to reduce the number of degrees of freedom. Results show that the bearing defects introduce supplementary critical speeds. The linear approach is unable to show the supplementary critical speeds which are obtained only by using non linear analysis.
\end{abstract}

Key Words: Fluid Bearing; Bearings with Defects; Modal Technique; Non-linear Analysis

\section{INTRODUCTION}

$\mathbf{T}$ he objective of the study presented here is to show the influence of bearing defects on the dynamical behavior of an elastic shaft. This defect is a wave of the rotor surface due to a manufacturing problem. Figure 1 presents this wave for two kinds of period $(2 \pi / 3$ et $2 \pi / 5)$. The amplitude of the defect is about the radius/10000 $\left(\mathrm{R}^{*} 10^{-4}\right.$ ) (a 2 micrometer wave for a $20 \mathrm{~mm}$ radius shaft).

In hydrodynamic lubrication the film thicknesses can be very small and the rotor defects can induce important variation of the pressure field. The study of the defect bearings has been developed by several authors and the objectives of these studies were to evaluate the minimum film thickness. Fantino [1973], Fantino and Frêne [1975] and Berthe et al. [1974] presented studies on the influence of the shape defects and surface roughness on the hydrodynamics of lubricated systems. They have especially shown that the Reynolds equation was not applicable when the defects become important. We have to use the viscous thin film equation developed by Berthe and Godet [1971].

Another domain of defect bearing study is the defects due to the elastic deformation of contact surfaces. This has been developed in the field of connecting rod bearing of petrol and diesel engines (Labouff and Booker [1985],
Fantino et al. [1979], Desailly et al. [1978], Pierre Eugène et al. [1983], Goodwin et Holmes [1982]). These deformations are induced by the large value of load resulting from the high hydrodynamic pressure due to the explosion and the connecting rod inertia. This elastohydrodynamic problem is a simultaneous approach of pressure field computation and deformation field calculation.

We consider in this study the case of constant defects on the rotor. Similar defects on the stator could have some influence on the pressure field but this effect is dynamically less important because it creates no dynamical perturbation. On the other hand defects located on the rotor, even for a stable speed, can create large orbits and resonant phenomena due to the shaft flexibility.

\section{THEORY}

\section{Bearing Model}

Figure 2 presents a bearing where $\mathrm{R}_{\mathrm{a}}$ and $\mathrm{R}_{\mathrm{c}}$ represent the rotor and stator radius. The reference $(\mathrm{Oc}, \mathrm{X}, \mathrm{Y}, \mathrm{Z})$ is a fixed reference centered on the stator center $\mathrm{O}_{c} \cdot \omega_{\mathrm{a}}$ is the speed of the shaft, the center of the rotor is represented by two systems of coordinates, a Cartesian system $(\mathrm{x}, \mathrm{y})$ 


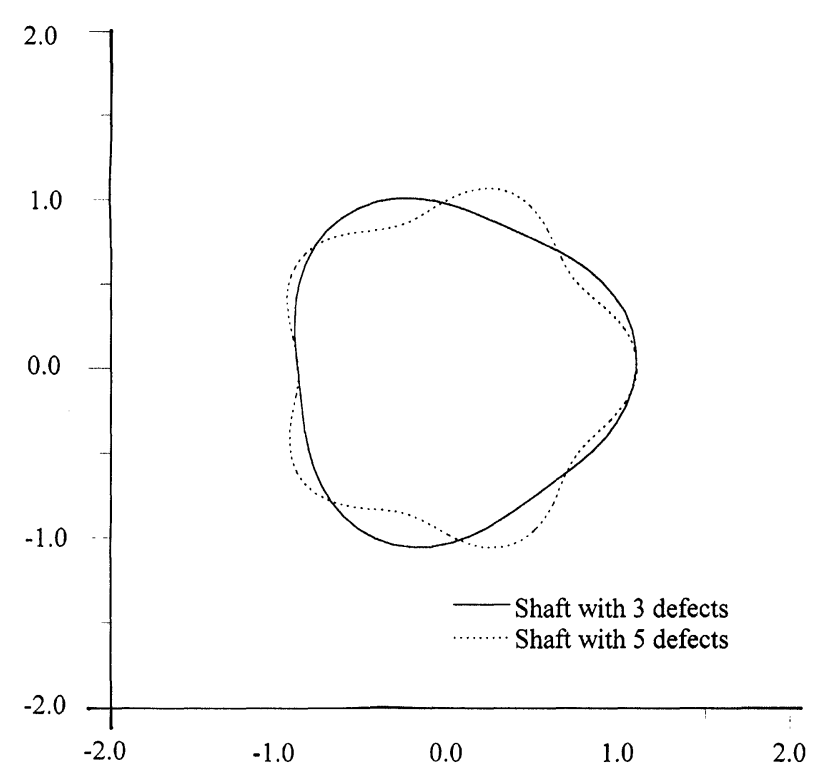

FIGURE 1 Bearing defects(shaft defects).

and a polar system $(\mathrm{e}, \psi)$ with e the distance $\left(\mathrm{O}_{\mathrm{a}}, \mathrm{O}_{\mathrm{c}}\right)$ and $\psi$ the angle between $\mathrm{X}$ axis and the centers line.

The manufacturing defects on the shaft are then described by a radial component $\delta_{\text {ra }}$. The radial clearance in the bearing being very small compared to the radius, one can develop the two surfaces and assimilate the stator surface to a plane. A point on the rotor surface has the following velocity:

$$
\begin{aligned}
\mathrm{U}_{2}=\omega_{\mathrm{a}} \mathrm{R}_{\mathrm{a}} \text { et } \mathrm{V}_{2} & =\dot{\mathrm{e}} \cos (\theta)+\mathrm{e} \dot{\psi} \sin (\theta)+\dot{\delta}_{\mathrm{ra}} \\
& +\mathrm{R}_{\mathrm{a}} \omega_{\mathrm{a}} \frac{\partial \mathrm{h}}{\partial \mathrm{x}} .
\end{aligned}
$$

With this hypothesis the thin film equation is the following:

$$
\begin{gathered}
\frac{\partial}{\partial x}\left[\frac{H^{3}}{\mu} \frac{\partial P}{\partial x}\right]+\frac{\partial}{\partial z}\left[\frac{H^{3}}{\mu} \frac{\partial P}{\partial z}\right]=6 \omega \frac{\partial h}{\partial \theta}-6 \omega \frac{\partial \delta_{r a}}{\partial \theta} \\
+12\left(\dot{\mathrm{e}} \cos (\theta)+\mathrm{e} \dot{\psi} \sin (\theta)+\delta_{r a}\right)
\end{gathered}
$$

$\mathrm{P}$ is the pressure field, $\mu$ is the fluid viscosity, $\mathrm{H}$ is the film thickness, $\mathrm{C}$ is the radial clearance, $\theta$ the angular parameter having its origin on the centers line and $\mathrm{H}=$ $\mathrm{h}+\delta_{\text {ra }}$ with $\mathrm{h}=\mathrm{C}+\mathrm{e} \cos (\theta)$.

This equation can be solved by finite differences with the Reynolds boundary conditions. However, the non linear analysis of the shaft implies heavy numerical calculation and one has opted to deal with the case of the short bearing. This assumption allows to simplify the differential equation: the circumferential flow is neglected, this is true when the length of the bearing remains small compared to the wave of the defect.

Then the pressure field can be obtained as follow:

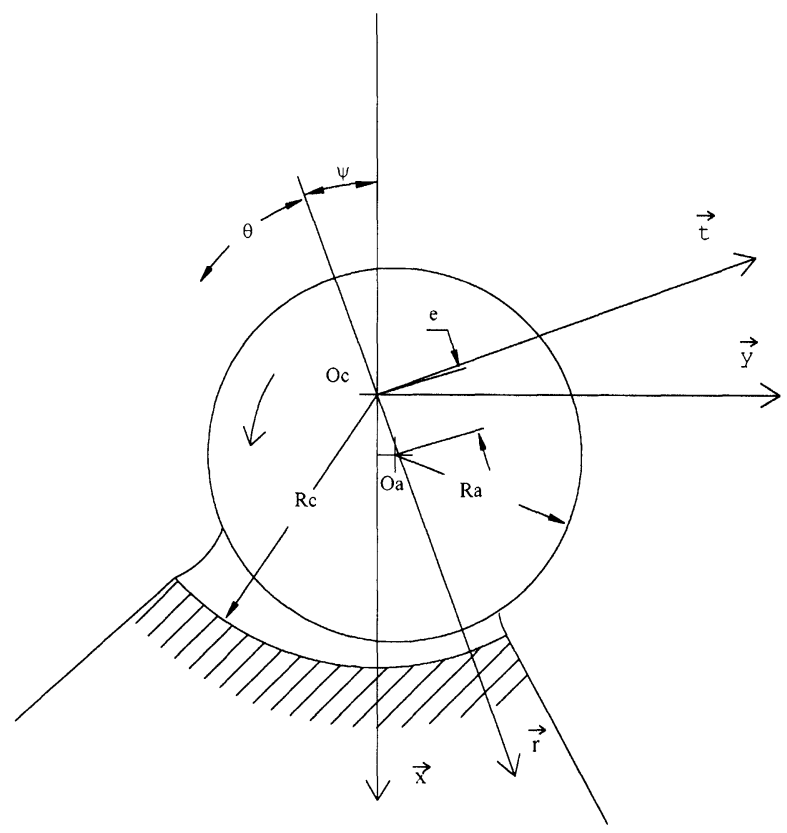

FIGURE 2 Bearing scheme.

$$
\begin{array}{r}
\mathrm{p}(\theta, \mathrm{z})=\frac{6 \mu \mathrm{C}}{\left(\mathrm{h}+\delta_{\mathrm{ra}}\right)^{3}}\left[\left(\psi-\frac{\omega}{2}\right) \varepsilon \sin \theta+\dot{\varepsilon} \cos \theta\right. \\
\left.-\frac{\omega}{2 \mathrm{C}} \frac{\partial \delta_{\mathrm{ra}}}{\delta \theta}\right]\left(\mathrm{z}^{2}-\frac{\mathrm{L}^{2}}{4}\right)
\end{array}
$$

The force components are obtained by integration of the pressure field with the following boundary conditions:

* Feed pressure on both sides of the bearing (atmospheric pressure)

* Gumbel assumption ( $\pi$ film) i.e. negative pressure are set to zero

Figures 3-a and 3-b show pressure fields obtained with a five defects shaft in comparison with a perfect shaft. The defect influence is very sensible.

- On Figure 3-a three pressure peaks appear, the maximum pressure is smaller than for a perfect shaft.

- Figure 3-b is obtained with exactly the same paramconsequence is an increase of the maximum pressure. eter, only the defect is displaced of a $10^{\circ}$ value. The 


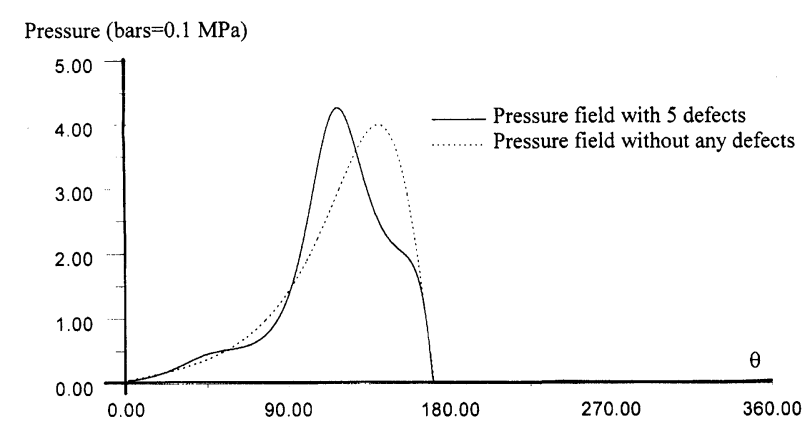

FIGURE 3-A Pressure field with and without defects (for a first angular position of the shaft).

\section{Shaft Model}

The rotor is modelled with typical beam finite elements including gyroscopic effects (Bonneau [1989ü. The differential system, with $\{\delta\}$ the node displacement vector is the following:

$$
[M]\{\dot{\delta}\}+[C]\{\dot{\delta}\}+[K]\{\delta\}=\left\{F_{u n b}\right\}+\left\{F_{n l}\right\}+\left\{F_{g r}\right\}
$$

Where:

[M]: mass matrix.

[C]: damping and gyroscopic matrix

$[\mathrm{K}]: \quad$ stiffness matrix.

$\left\{F_{\text {unb }}\right\}$ : Unbalance forces.

$\left\{F_{n l}\right\}$ : Non linear bearing forces.

$\left\{F_{g r}\right\}$ : Gravity forces.

This system has $4(n+1)$ degrees of freedom ( $n$ is the number of nodes). The iterative non linear computation will be very expensive in computer time. To reduce degrees of freedom a modal approach is used. The

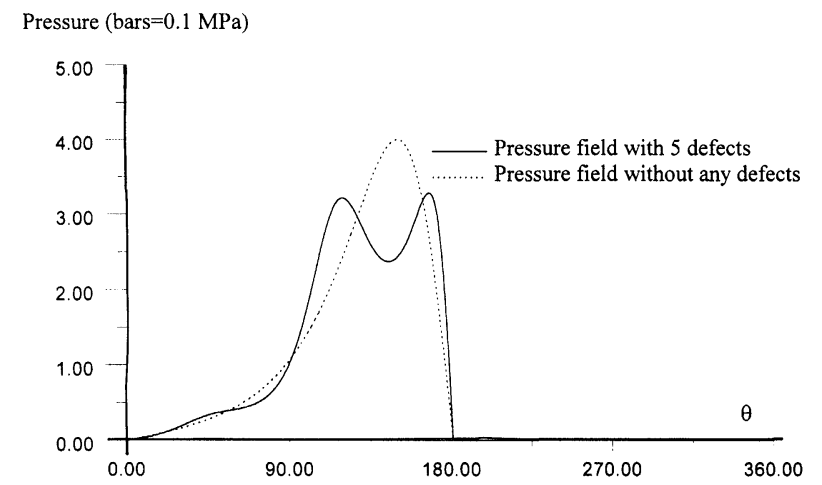

FIGURE 3-B Pressure field with and without defects (for another angular position of the shaft). bearing is first modelled by a linear stiffness and then the fundamental principle of mechanics on the rotor could be written:

$$
[\mathrm{M}]\{\dot{\delta}\}+\left(\left[\mathrm{K}_{\mathrm{r}}\right]+\left[\mathrm{K}_{\text {bearing }}\right]\right)\{\delta\}=0
$$

The solution has the following form: $\{\delta\}=\left\{\delta_{0}\right\} \mathrm{e}^{r t}$ and the first 6 modes are calculated. Lacroix [1988] has shown that 6 modes are enough to obtain the acceptable precision. A change of variable is done in the following form: $\{\delta\}=[\psi]\{q\}$ with $\{\psi\}$ the matrix obtained with modal vectors. $\left\{\psi_{i}\right\}$ and $\{\mathrm{q}\}$ is the modal vector of displacement.

A new system is written where the bearing effect appears in the modal stiffness matrix.

$$
[\mathrm{m}]\{\ddot{\mathrm{q}}\}+[\mathrm{c}]\left\{\dot{\mathrm{q}}+\left[\mathrm{k}^{\prime}\right]\{\mathrm{q}\}=\{\mathrm{f}\}\right.
$$

with:

$$
\begin{gathered}
{[\mathrm{m}]=[\psi]^{\mathrm{t}}[\mathrm{M}][\psi]} \\
{[\mathrm{c}]=[\psi]^{\mathrm{t}}[\mathrm{C}][\psi]} \\
{\left[\mathrm{k}^{\prime}\right]=[\psi]^{\mathrm{t}}[\mathrm{K}][\psi]} \\
\{\mathrm{f}\}=[\psi]^{\mathrm{t}}\{\mathrm{F}\}
\end{gathered}
$$

To do a non linear calculus the linear bearing effect $\left[\mathrm{K}_{\text {bearing }}\right]$ must be substracted from modal stiffness [ $\left.\mathrm{k}^{\prime}\right]$ and must be introduced as non linear effect

Then

$$
[\mathrm{m}]\{\ddot{\mathrm{q}}\}+[\mathrm{c}]\{\ddot{\mathrm{q}}+[\mathrm{k}]\{\mathrm{q}\}=\{\mathrm{f}\}+\{\mathrm{Fnl}\}
$$

with

$$
[\mathrm{k}]=\left[\mathrm{k}^{\prime}\right]=\left[\mathrm{k}^{\prime}\right]-[\psi]^{\prime}\left[\mathrm{k}_{\text {bearing }}\right]\{\psi\}
$$

Remark: The value of $\left[\mathrm{K}_{\text {bearing }}\right]$ is delicate to select. Kassai [12] has shown that it was necessary to take an intermediate value of bearing stiffness (for computing the modal basis). The reason is to obtain a modal basis that allows to have displacement in the bearing nodes.

\section{Non Linear Simulation}

The simulation of the non linear dynamical behavior of the flexible rotor is a step by step approach done in the 
modal basis. The flow diagram is as follows:

a) Beginning with initial values of modal positions and velocities

b) Calculus of external modal forces (unbalance, weight,...)

c) Calculus of real displacements and velocities in bearings (by modal basis change)

d) Non linear bearings forces calculus (in the real basis)

e) Computation of all forces in the modal basis (by modal basis change)

f) Modal accelerations computation

g) Time integration (by variable step Euler method)

h) Shaft speed is incremented

i) The process begins in b)

Remark: This numerical scheme has been validated by comparison to an experimental work [(Bonneau [1989], Kassai [1989] and Bonneau et al. [1989]); it was a study of an elastic rotor mounted in a non linear squeeze film damper.

\section{RESULTS}

To illustrate this work a very simple model of shaft which is symmetrical and mounted in two identical bearings has been chosen. It is presented on Figure 4 .

The data of the bearing are the following:

The length $\mathrm{L}=0.01 \mathrm{~m}$; the radius $\mathrm{R}=0.02 \mathrm{~m}$; the radial clearance $\mathrm{C}=0.0410^{-3}$; the viscosity $\mu=0.01$ Pa.s, the static load is $300 \mathrm{~N}$ which is applied on the middle of the rotor (point 2), the velocity varies from $1000 \mathrm{rpm}$ to $6000 \mathrm{rpm}$ in $15 \mathrm{~s}$.

\section{Shaft Behavior}

The first calculation concerns the non linear behavior of the shaft without any defects in the bearing. Figure 5 presents the non linear unbalance response of the shaft. The amplitudes in the $\mathrm{x}$ and $\mathrm{y}$ directions for the middle of the shaft (point B on Figure 4) and in the bearing

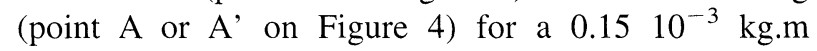

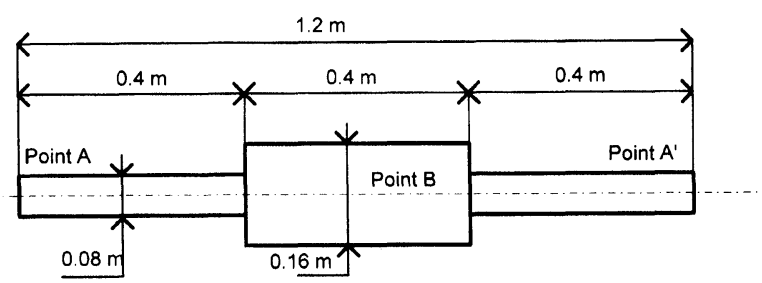

FIGURE 4 geometrical data of the shaft.

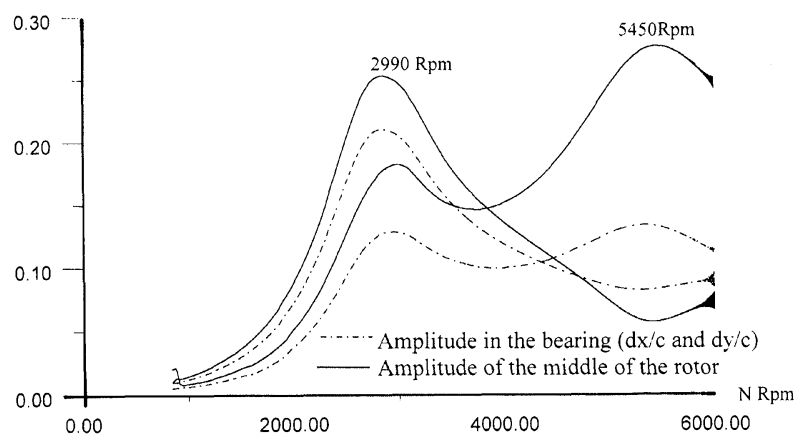

FIGURE 5 Non linear shaft behavior (without defect on the shaft).

unbalance are plotted. All the amplitudes presented in this work are non dimensional (amplitude/radial clearance ratio). Two critical speeds appear at $2990 \mathrm{Rpm}$ and $5450 \mathrm{Rpm}$.

\section{Defects Influence}

Two sorts of defects influence will be studied now,a bearing with 2 defects and one with 3 defects. The defect amplitude is about $10 \%$ of the radial clearance.

Figure 6-a presents the trajectories of point 1 (in the bearing) and Figure 6-b trajectories of point 2 (middle of the rotor). These results are obtained with two defects bearing.

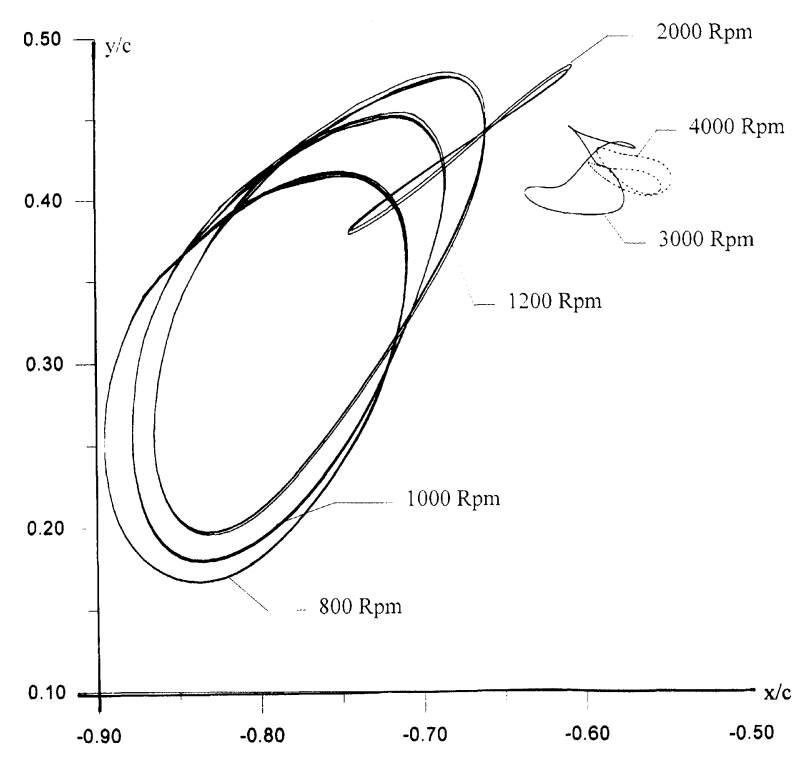

FIGURE 6-A Trajectory of the shaft in the bearing (point A). 


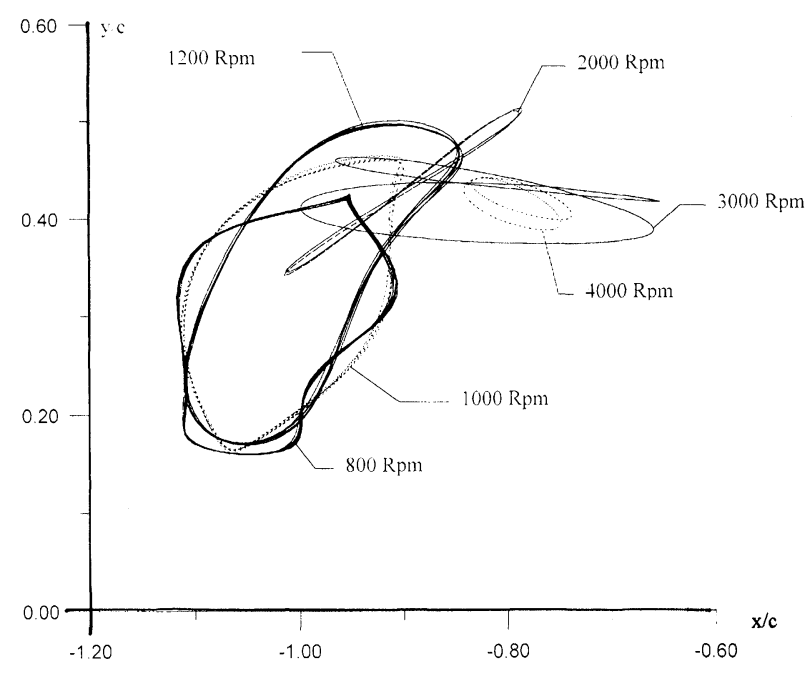

FIGURE 6-B Trajectory of the middle of the rotor (point B).

Trajectories are very original, they are addition of an unbalance effect and of the effect of the bearing defects.

Figure 7 presents the trajectory obtained at $4000 \mathrm{Rpm}$ in the bearing, there is a precession with two loops during one revolution of the shaft $($ a $2 \times 4000=8000$ Rpm frequency appears).

Now some results obtained for a variable speed from $1000 \mathrm{Rpm}$ to $6000 \mathrm{Rpm}$ with two kinds of unbalance forces: a small one $\left(0.110^{-4} \mathrm{~kg} . \mathrm{m}\right)$ and a large one $(0.15$ $10^{-3}$ kg.m).

Figures 8-a and 8-b present the amplitudes dx and dy (introduced on Figure 7) for the two sorts of bearings and

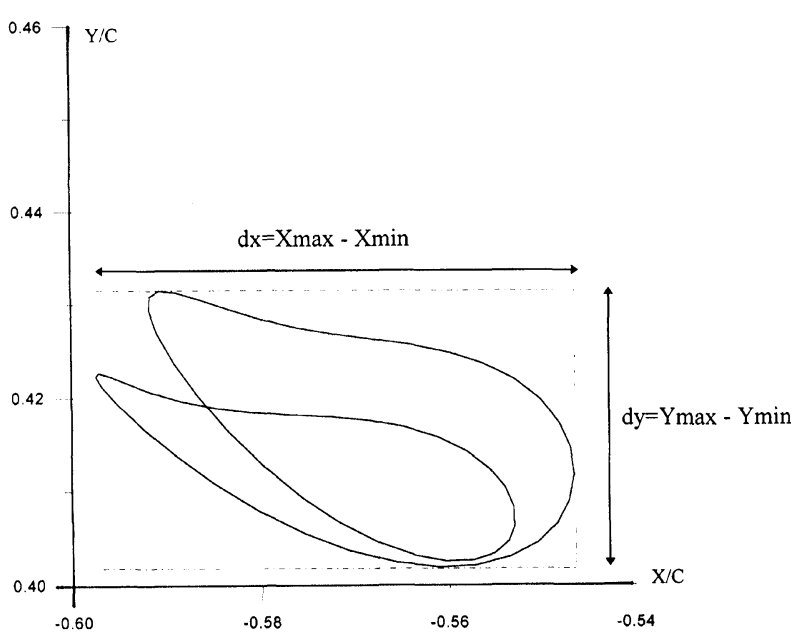

FIGURE 7 trajectory of a bearing with two defects and small unbalance (4000 rpm).

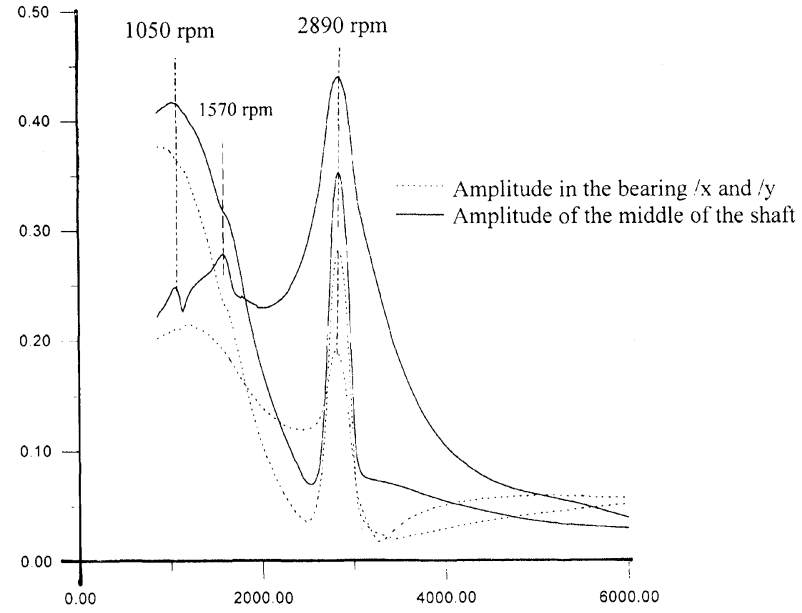

FIGURE 8-B Amplitudes of the shaft for a two defects bearing and a small unbalance.

for the small unbalance (the effect of unbalance are small compared to the effect of defects). New critical speeds clearly appear equal to the shaft critical speed (figure 5) divided by the number of defects (1570 Rpm and 2890 Rpm for the two defects; $1150 \mathrm{Rpm}$ and $1990 \mathrm{Rpm}$ for the three defects). The rotor critical speed is not excited because of the small unbalance value.

Figures $8 \mathrm{c}$ and $8 \mathrm{~d}$ show the results obtained with an important unbalance, the shaft synchronous critical speeds appear $(\approx 3000 \mathrm{Rpm}$ and $5400 \mathrm{Rpm})$.

It is interesting to notice that, in the case of the two defects bearing (Figure 8-c) two critical speeds are

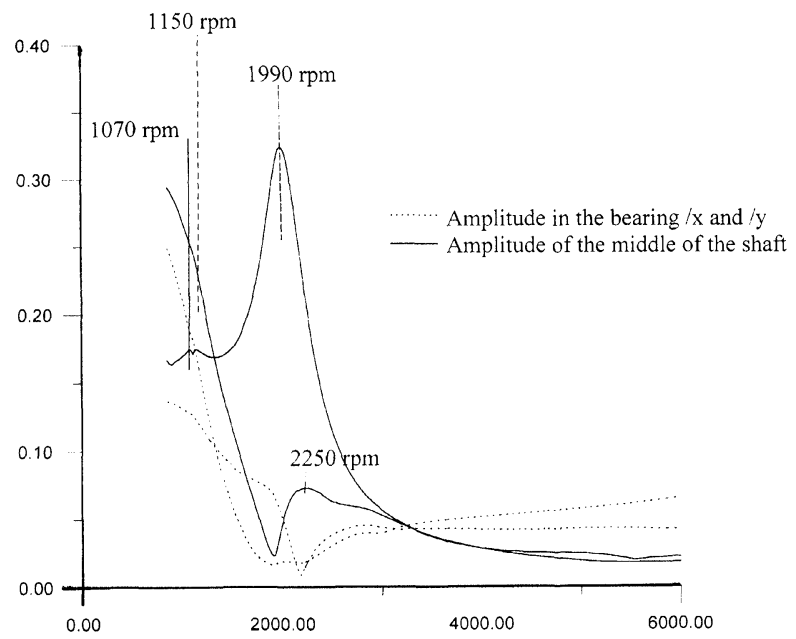

FIGURE 8-B Amplitudes of the shaft for a three defects bearing and a small unbalance. 


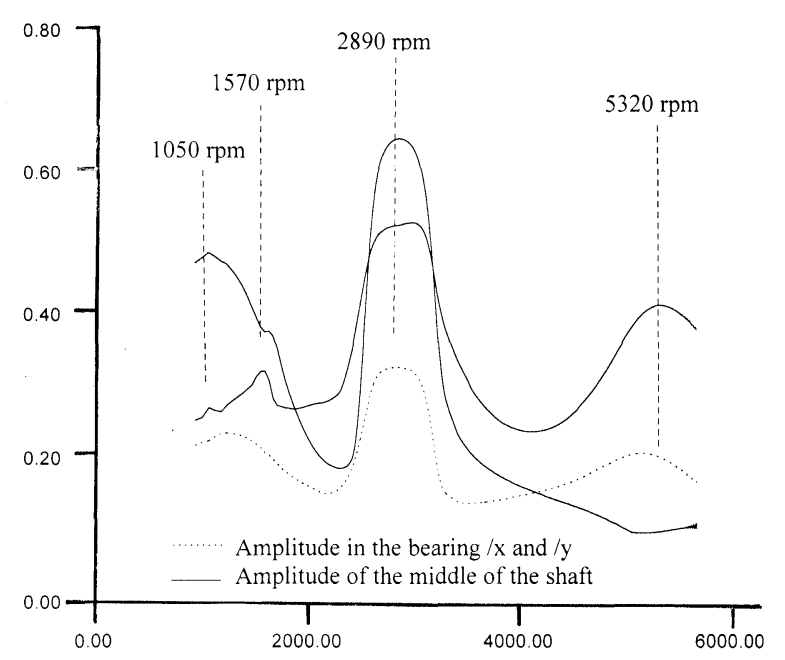

FIGURE 8-C Amplitudes of the shaft for a two defects bearing and a high unbalance.

superposed (the synchronous speed $3000 \mathrm{Rpm}$ excited by the unbalance and the $5400 \mathrm{rpm}$ speed divided by $2 \approx$ 2700 Rpm).

For the three defects bearing (Figure 8-d) this superposition does not exist, there are four distinct frequencies.

\section{CONCLUSION}

The work presented here shows the important dynamical effect of some periodic defects in a bearing. It has been demonstrated that these defects can excite the critical speeds even if there are no unbalance forces. This effect is more important if the static load is important. The non linear analysis of the shaft is absolutely indispensable: a linear model cannot take into account the dynamical

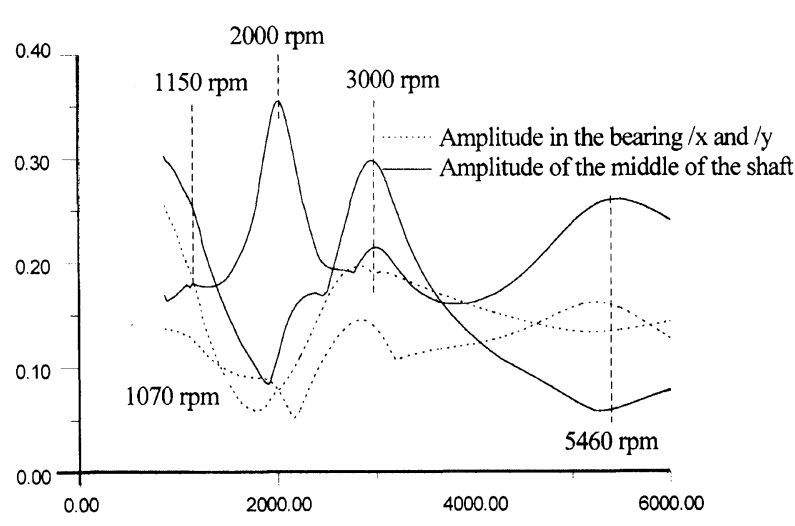

FIGURE 8-D Amplitudes of the shaft for a three defects bearing and a high unbalance. effects of this defect. The elastic model of the shaft is here very useful to show different critical speeds. The trajectories obtained with our new model are original: they change with the rotational speed, there is superposition of two phenomena unbalance effect and bearings' defects.

\begin{tabular}{|c|c|}
\hline \multicolumn{2}{|c|}{ Nomenclature } \\
\hline $\mathrm{C}$ & Radial clearance (m) \\
\hline e & distance $\left(\mathrm{O}_{\mathrm{a}}, \mathrm{O}_{\mathrm{c}}\right)(\mathrm{m})$ \\
\hline $\mathrm{H}$ & Film Thickness (m) $\mathrm{H}=\mathrm{h}+\delta_{\mathrm{ra}}$ \\
\hline $\mathrm{h}$ & $\begin{array}{l}\text { Theoritical film thickness }(\mathrm{m}) \mathrm{h}=\mathrm{C}+\mathrm{e} \cos \\
(\theta)\end{array}$ \\
\hline $\mathrm{L}$ & Bearing length (m) \\
\hline$n$ & The number of nodes \\
\hline $\mathrm{O}_{\mathrm{c.} .}$ & the stator center \\
\hline$(\mathrm{Oc}, \mathrm{X}, \mathrm{Y}, \mathrm{Z})$ & a fix reference \\
\hline$P$ & Pressure field $(\mathrm{Pa})$ \\
\hline $\mathrm{R}_{\mathrm{a}}$ & Shaft radius $(\mathrm{m})$ \\
\hline $\mathrm{R}_{\mathrm{c}}$ & Stator radius $(\mathrm{m})$ \\
\hline $\mathrm{U}_{2}$ and $\mathrm{V}_{2}$ & $\begin{array}{l}\text { speed components of the rotor in a local refer- } \\
\text { ence }(\mathrm{m} / \mathrm{s}) \text {. }\end{array}$ \\
\hline$(\mathrm{x}, \mathrm{y})$ & Cartesian coordinates $(\mathrm{m})$ \\
\hline$\delta_{\text {ra }}$ & manufacturing defects on the shaft (m) \\
\hline$\delta$ & Node displacment $(\mathrm{m})$ \\
\hline$\psi_{\mathrm{a}}$ & the speed of the shaft $(\mathrm{rd} / \mathrm{s})$ \\
\hline$(e, \psi)$ & Polar coordinates \\
\hline$\psi$ & angle between $\mathrm{X}$ axe and the center line \\
\hline$\mu$ & Dynamic viscosity (Pa.s) \\
\hline$\theta$ & $\begin{array}{l}\text { The angular parameter being its origin one the } \\
\text { center line. }\end{array}$ \\
\hline$[\mathrm{C}]$ & damping and gyroscopic matrix (N.s/m) \\
\hline$[\mathrm{K}]$ & stiffness matrix. (N/m) \\
\hline$\left[\mathrm{K}_{\mathrm{r}}\right]$ & rotor flexion stiffness matrix. $(\mathrm{N} / \mathrm{m})$ \\
\hline$\left[\mathrm{K}_{\text {bearing }}\right]$ & Bearing stiffness (N/m) \\
\hline$[\mathrm{M}]$ & mass matrix. (kg) \\
\hline$\left\{F_{u m b}\right\}$ & Unbalance forces. $(\mathrm{N})$ \\
\hline$\left\{F_{n l}\right\}$ & Non linear bearing forces. $(\mathrm{N})$ \\
\hline$\left\{F_{g r}\right\}$ & Gravity forces. (N) \\
\hline$[\psi]$ & The modal matrix \\
\hline$\left\{\psi_{t}\right\}$ & Modal vector \\
\hline
\end{tabular}

\section{References}

Berthe D., Godet M., 1971 "Equation de l'écoulement laminaire entre deux paroix rapprochés en mouvement relatif' C. R. Académie des Sciences, Paris, t. 272, série A, p. 1010-1013.

Berthe D., Fantino B., Frêne J., Godet M., 1974. "Influence of the shape defects and surface roughness on the hydrodynamics of lubricated systems" Journal Mechanical Engineering Science. Institution of Mechanical Engineers, vol. 16, n³, pp 156-159.

Bonneau O., Kassai A.,Frêne J., Der Hagopian J., 1989 "Dỵnamical 
behavior of an elastic rotor with a squeeze film damper" Eurotrib 1989, Heslsinki, Finland, Proceeding vol 4 pp 145-149.

Bonneau O. 1989 "Comportement statique et dynamique de ligne d'arbre montée sur paliers fluides: influence des caractéristiques des paliers". Thèse de l'Université de POITIERS 2 février 1989.

Desailly R., Fantino B., Fréne J., 1978 "Hydrodynamics of an Elasic Connecting Rod Bearing: Comparison of Theoretical and Experimental Results". Fifth Leeds-Lyon Symposium on Tribology, Leeds, England, September 1978. Proceeding IME "Elastohydrodynamics and related Topics" pp 329-336, 1979.

Fantino B., "Influence des défauts de formes dans la lubrification hydrodynamique" Thèse de Doctorat de Spécialité Lyon 1973.

Fantino B., Frêne J., 1975 "Charge tournante et défauts de forme en régime transitoire" Mécanique, Matériaux Electricité, revue du G.A.M.I. n³08-309, p 40-44, août-septembre 1975.

Fantino B., Fréne J., Du Parquet J., 1979 "Elastic Connecting-Rod Bearing with Piezoviscous Lubricant: Analysis of the Steady-State Characteristics", Tran. ASME, J.O.L.T., vol. 101, n², pp 190-200, 1979.
Goodwin G., Holmes R., 1982 "Bearing Deformation and Temperature Distribution in Dynamically-Loaded Engine Bearings" Tribology-key to the Efficient Engine, Inst. Mech. Eng. Conference Publications, 1982, paper C2/82, pp. 9-15.

Kassai A., 1989 "Contribution à l'Etude Dynamique des Rotors Amortis" Thèse de l'INSA de Lyon soutenue le 6 juillet 1989.

Labouff G. A., Booker J.F., 1985 "Dynamically-loaded Journal Bearings A Finite Element Treatment for Rigid and Elastic Surfaces" Transaction of ASME, Journal of Tribology, vol. 4, 1985, pp 505-515.

Lacroix J., 1988 “Comportement Dynamique d'un rotor au passage des vitesses critiques" Thèse de l'INSA de Lyon soutenue le 13 juillet 1988.

Pierre-Eugène J., Frêne J., Fantino B., Roussel G, Du Parquet J., 1983 "Theory and Experiments on Elastic Connecting Rod Bearings Under Steady State Conditions" 9th Leeds Lyon Symposium on Tribology, Tribology of Reciprocating Engines, Butterworths, 1983, pp 49-54. 

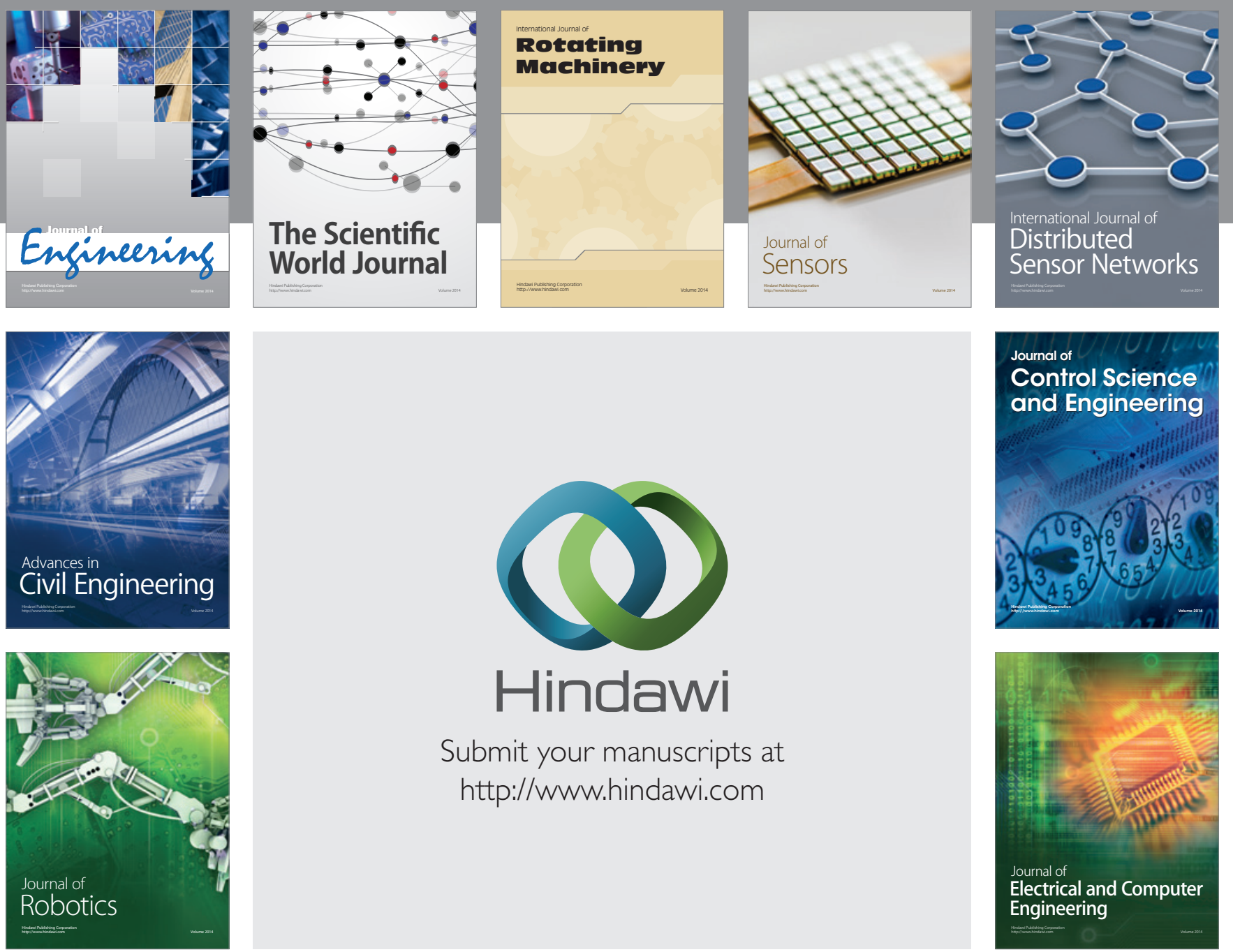

Submit your manuscripts at

http://www.hindawi.com
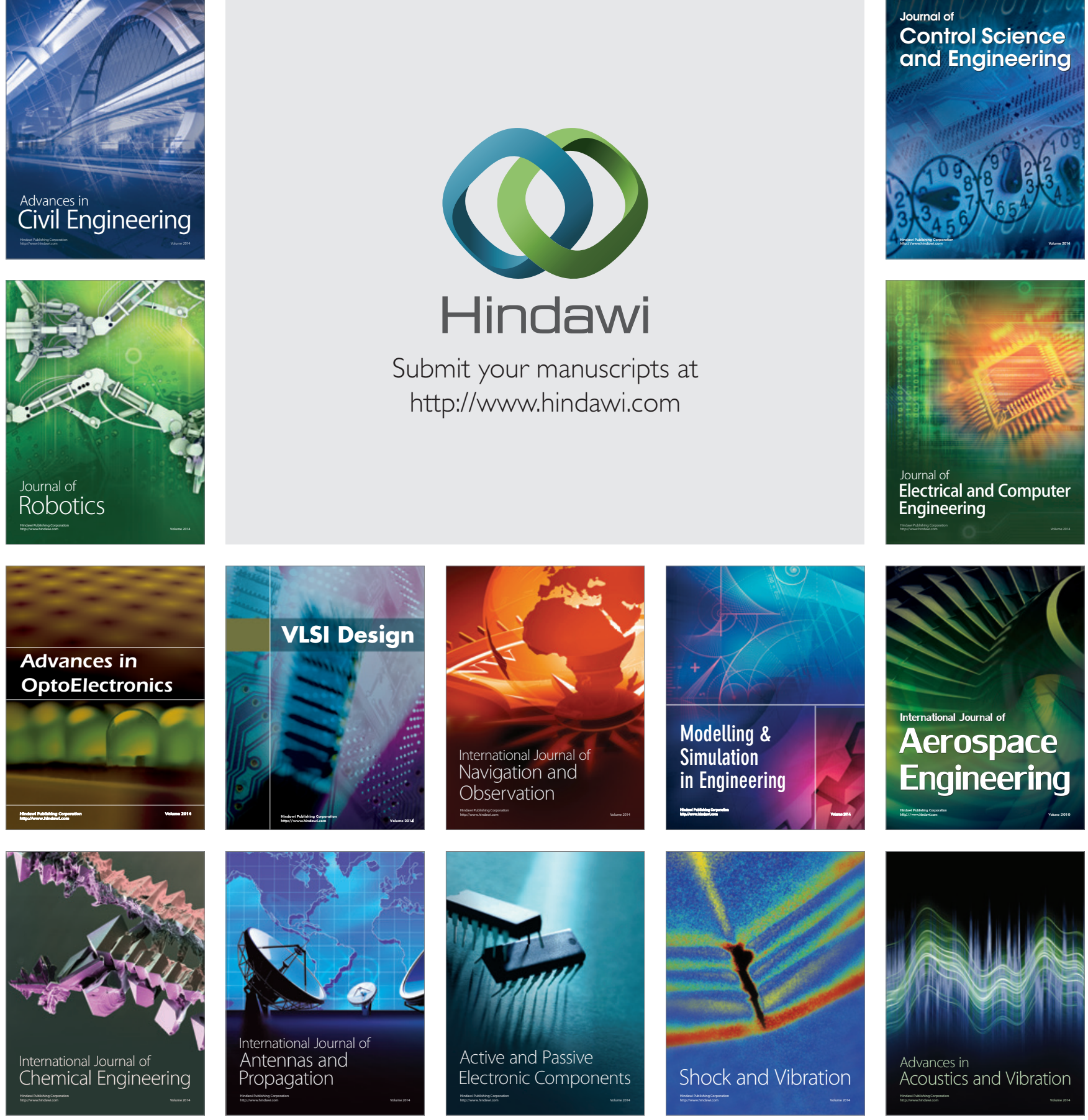